\title{
CHARACTERISTIC TAPHANOMIC MORPHOLOGIES IN FOSSIL SOFT-TISSUES AND THEIR REPRODUCTION IN ACTUALISTIC NECROLYTIC EXPERIMENTS.
}

\author{
WILBY, Phil R., Dept. of Earth Sciences, The Open University, \\ Walton Hall, Milton Keynes, Buckinghamshire, MK7 6AA, UK.
}

Soft-tissues replaced by hydroxyapatite are exceedingly abundant in fossil fish from the Santana Formation (Lower Cretaceous) of Ceara, NE Brasil. A number of tissues are often phosphatized within an individual specimen and may include portions of the alimentary tract, skeletal muscle, dermis, gill apparatus and ovaries. The level of structural detail displayed by these tissues varies considerably between individual fish but is relatively constant within any single specimen. In some, sub-cellular resolution is the norm, whilst in others only gross morphological detail is preserved.

Frequently, certain tissues such as gill filaments and their secondary lamellae; epithelial cells of the gut wall; and, striated muscle fibres, preserve a number of different morphologies. In the latter for example, a continuum exists between homogeneously mineralized fibres which are almost indistinguishable from living muscle, and muscle which is disrupted by exceptionally well developed and irregularly spaced banding. In the same specimens, both the sarcolema and cell nucleii may display varying degrees of distortion. These characteristic morphologies reflect the gradual loss of structural integrity accompanying a period of post-mortem decay prior to and/or during permineralization.

High resolution TEM and SEM studies of structures produced at progressive stages of soft-tissue decay in modern fish, confirm the necrolytic origin of these morphologies. The timing of their appearance under specified conditions is remarkably reproducible. Certain parameters such as the ambient water temperature and salinity appear to have considerable influence over the rapidity of decay, whereas others, including the levels of oxygen and the presence of an established bacterial community have less, especially over short periods.

By cross-referencing certain taphanomically produced structures, estimates of both the timing of phosphatization and the likely bottom water conditions of the Santana Formation "lagoon" may be made. 